2. To: (Receiving Organization)

Fluor Daniel Hanford

SNF Project Direction

5. Proj./Prog./Dept./Div.:

SNF Project

8. Originator Remarks:

Project Execution Plan (PEP) for Sludge Treatment System Subproject for approval.

11. Receiver Remarks: 11A. Design Baseline Document? [] Yes [X] No
3. From: (Originating Organization) Numatec Hanford Corporation SNF Projects

6. Design Authority/ Design Agent/Cog. Engr.:

W. W. Rutherford

4. Related EDT No.:
N/A

9. Equip./Component No.: $\mathrm{N} / \mathrm{A}$

10. System/Bldg./Facility: N/A

12. Major Assm. Dwg. No.:

N/A

13. Permit/Permit Application No.: $\mathrm{N} / \mathrm{A}$

14. Required Response Date: $3 / 03 / 98$

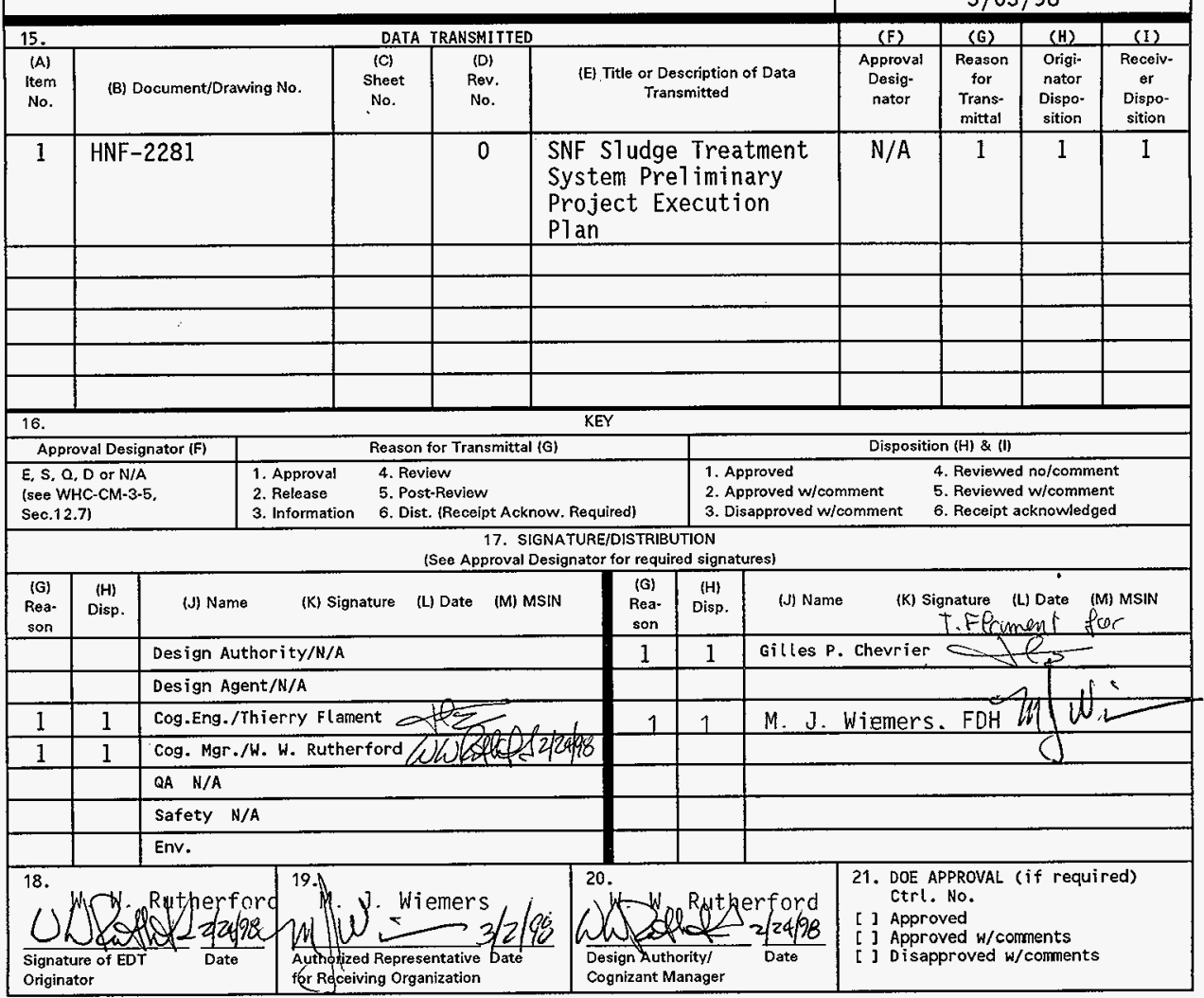

BD-7400-172-2(05/96) GEF097 


\section{SNF SLUDGE TREATMENT SYSTEM PRELIMINARY PROJECT EXECUTION PLAN}

Thierry Flament

Numatec Hanford Corporation, Richland, WA 99352

U.S. Department of Energy Contract DE-AC06-96RL13200

EDT/ECN: 623957

Org Code: $8 \mathrm{C} 450$

UC: $A H A A^{g e} 2000$

B\&R Code: EW7040000

Charge Code: E58590

Total Pages: $-5 g, 51$

Key Words: SNF SLUDGE TREATMENT SYSTEM PRELIMINARY PROJECT EXECUTION PLAN

Abstract: This PEP defines the management strategy for a project to provide a process system to receive and chemically treat radioactive sludge currentiy stored in the $100^{\circ} \mathrm{K}$ Area Fuel Retention Basins.

TRADEMARK DISCLAIMER. Reference herein to any specific commercial product, process, or service by trade name, trademark, manufacturer, or otherwise, does not necessarily constitute or imply its endorsement, recomendation, or favoring by the United States Government or any agency thereof or its contractors or subcontractors.

Printed in the United States of America, To obtain copies of this document, contact: Document Control Services, P.O. Box 950, Mailstop H6-08, Richland WA 99352, Phone (509) 372-2420;

Fax (509) 376-4989.

$\frac{\text { Hana }}{\text { pelease Approval }}$

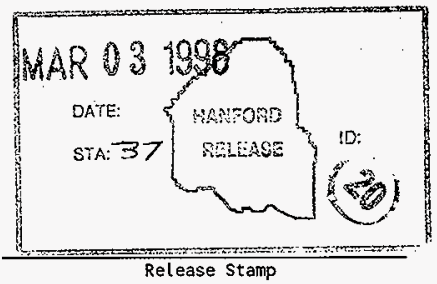




\title{
SNF SLUDGE TREATMENT SYSTEM PRELIMINARY PROJECT EXECUTION PLAN
}

\author{
HNF-2281 \\ Revision 0
}

February 19, 1998 
SNF Sludge Treatment System

Rev $O$

Preliminary Project Execution Plan

HNF-2281

\subsection{INTRODUCTION}

The Fluor Daniel Hanford, Inc. (FDH) Project Director for the Spent Nuclear Fuel (SNF) Project has requested Numatec Hanford Company (NHC) to define how we would manage a new subproject to provide a process system to receive and chemically treat radioactive sludge currently stored in the $100 \mathrm{~K}$ Area fuel retention basins. The subproject, named the Sludge Treatment System (STS) Subproject, provides and operates facilities and equipment to chemically process K Basin sludge to meet Tank Waste Remediation System (TWRS) requirements. This document sets forth the NHC management approach for the STS Subproject and will comply with the requirements of the SNF Project Management Plan (HNF-SD-SNFPMP-011).

This version of this document is intended to apply to the initial phase of the subproject and to evolve through subșequent revision to include all design, fabrication, and construction conducted on the project and the necessary management and engineering functions within the scope of the subproject.

As Project Manager, NHC will perform those activities necessary to complete the STS Subproject within approved cost and schedule baselines and turn over to FDH facilities, systems, and documentation necessary for operation of the STS.

\subsection{MANAGEMENT APPROACH}

NHC will build on its SGN heritage to manage this project with sound project management principles from the very beginning while maintaining a high level of technical excellence. With an appropriate balance of French and American resources we will apply our experience in designing, building and operating complex nuclear process systems around the world. We will assign an experienced Project Manager supported by a qualified team of technical staff who combine the best of French, American and Hanford capabilities. We will implement effective project management principles to establish and control the project baseline.

Our approach places emphasis on developing a solid cost, schedule, and technical baseline early in the project and strong management to firmly adhere to that baseline. Our experience has shown that technical and safety issues that are not resolved with durable solutions are often the root cause for cost and schedule increases later in the project. Our early activities will put significant emphasis on resolving technical and safety issues as we develop the baseline to minimize project perturbations in the execution phase. 


\subsection{PROJECT SCOPE}

The SNF Project will remove spent nuclear fuel and other materials from the $100-\mathrm{K}$ Basins as a remediation effort. The $\mathrm{K}$ Basins store spent fuel, but contain substantial quantities of sludge and debris. Sludge has accumulated in the basins as a result of fuel oxidation and general debris being deposited. The SNF Project will remove the sludge. This subproject will provide a transportation system from the basin to the processing facility, the treatment facility to meet the TWRS and Environmental Restoration Disposal Facility (ERDF) requirements and the transport system to transfer the end-products to the appropriate Hanford locations for storage and/or disposal.

TWRS has established requirements for treating the sludges and have documented them in the K Basin Sludge Pretreatment Requirements Summary (HNF-SD-TWR-OCD-001). The SNF Project completed a Preconceptual Design Report (HNF-SD-SNF-PCR-002) for the K Basin Sludge Removal System Sludge Pretreatment System. The Preconceptual Design assumed chemical treatment of the sludges to meet the TWRS requirements. Based upon our review and understanding of the treatment options, $\mathrm{NHC}$ considers chemical treatment to be the most feasible solution to meeting the requirements and will use it as a basis for proceeding with the project. We will remain open to other alternatives if viable options, which reduce cost, improve schedule, or improve safety, are identified during our concept studies.

The $\mathrm{K}$ Basin sludges mainly consist of metallic uranium, uranium hydride, alumina and silica, iron hydroxide, metallic zirconium and ion exchange (IX) resins. The main contaminants of concern are plutonium and other transuranics (TRU), fission products, and polychlorinated biphenyl (PCB).

The sludges currently do not meet the requirements for the Hanford Tank Farms mainly due to particle size, criticality and PCB content. In addition, the metallic uranium content raises safety concerns during the transport to or storage in the tanks due to pyrophoricity.

The proposed treatment will result in a separated PCB product in addition to the treated sludges. This treatment consists of dissolution in nitric acid of the maximum possible fraction of the sludges which is expected to remove a large part of the radionuclides from the residual nonsoluble solids.

The PCB is expected to mainly remain in the non-soluble residual solids, which will constitute the bulk of the separated PCB product. In order to achieve compliance with Hanford Solid 
Waste Acceptance Criteria, this product may need additional radionuclide removal (mainly TRU). The PCB is expected to partially vaporize during the dissolution operation. Off gas treatment will result in PCB loaded solids which will be the rest of the separated PCB product. The dissolution solution will be the treated sludge product after isotopic dilution for criticality risk control and neutralization for chemical compatibility with tank material: This product may need additional PCB removal to comply with Tank Farm requirements.

Interfaces between the STS and other subprojects within SNF, as well as other Hanford programs, must be identified, documented, and controlled. The STS subproject will manage these interfaces with the other organizations. Work activities to address issues associated with the receipt of products produced by the subproject, such as safety analysis for Tank Farms, are included in the subproject scope.

\subsection{PROJECT NEAR TERM STRATEGY}

There are significant technical and safety uncertainties associated with the processing of the $\mathrm{K}$ Basin sludge. (See Appendix A for a description of the uncertainties.) These uncertainties must be addressed before a defensible cost and schedule baseline can be established.

We have developed a plan to reduce the risks to an acceptable level and still meet the customers needs to complete the project on time. We have a two phase approach to project definition as we develop the concepts and produce the project baseline. This approach allows the project to resolve the significant technical and safety issues early in the project schedule and obtain customer acceptance of the solutions prior to commitment to production of the project baseline.

The first phase, Concept Definition, is structured to provide the customer with enough information to make a decision on the path forward for the project with a clear understanding of the risks. This phase will consist of developing a series of studies and tests aimed at resolving the technical and safety uncertainties concurrent with the other engineering activities necessary to produce a design. The design tasks at this stage will help develop a preliminary cost estimate and schedule and confirm that the implementation of the chosen processes is achievable. The reference concept will be documented in process flow diagrams (PFDs) and a Functional Design Criteria (FDC): An initial project execution strategy, along with a preliminary cost estimate and schedule for the project will also be developed.

The second phase, Baseline Definition, will produce the project baseline. We will build on the design developed in the Concept Definition phase and produce sketches and a Design Requirements Document (DRD) to guide the designer of the system, and prepare a preliminary 
hazards analysis/preliminary safety evaluation (PHA/PSE). Additional studies or testing may be identified to resolve assumptions and/or technical issues identified in the Concept Definition phase. If required, these studies or tests would be performed concurrently with the conceptual design. The project execution strategy will be updated to determine the best approach to design/fabricate/install the system. A revised project schedule and cost estimate will also be prepared. All of these products will be equivalent to a conceptual design and will form the basis for the project baseline. This baseline will be sufficient to allow immediate commencement of the project execution phase.

This two phase approach to project definition allows the project to reduce risk, develop cost effective solutions and produce a solid baseline while meeting customer expectations.

Specific needs to address the Multi-Year Work Plan inputs, the project validation activities by $\mathrm{DOE}$, and other activities, will be included in the plan when the needs are better defined.

\subsection{SCHEDULE AND COST ESTIMATE}

The schedule shown in Figure 1 is based on the FDH authorization to proceed given during a meeting on February 02, 1998. The schedule also assumes that the formal authorization of FDH will be transmitted by February 21, 1998. The duration for the Concept Definition phase is approximately six months. A decision point by FDH is scheduled early in August to confirm the concept and the preliminary cost estimate and schedule.

Following the FDH decision to proceed, preparation of the project baseline will begin. The duration for this phase is approximately seven months. The plan shown on Figure 1 for the Baseline Definition phase is preliminary and may need to be revised based on the concept and strategy developed in the first phase. It is expected that the project baseline would be approved by April 1999 to allow immediate initiation of project execution.

Figure 2 shows the cost estimate for the Concept Definition and Baseline Definition phases. The total cost for the first phase is $\$ 2,535,000$. The cost for the second phase is $\$ 1,961,000$, which includes a $25 \%$ contingency. The cost estimate shown in Figure 2 does not include the costs associated with preparation of this PEP.

Figure 3 shows a monthly staffing plan for the first two phases.

For preparation of the cost estimate and schedule we have assumed the following: 
- DE\&S Hanford, Inc. (DESH) costs associated with on-going activities and transition of the project to NHC are funded separately and not included in the estimate

- Solid Waste conditioning and disposal costs are funded separately and are not included in the estimate (we have included studies to determine the best approach to conditioning to Hanford Solid Waste Acceptance Criteria)

- NHC will establish feed and product transport criteria to interface with the treatment system (we have included studies to assess transport options and safety requirements)

- NHC will have direct access to the regulators for information exchange

- The decision maker for the STS Subproject will be FDH (not.DOE-RL)

- Funding will be available in FY 98 and beyond to support the established project baseline

See Appendix B for a list of technical studies and deliverables and Appendix $\mathrm{C}$ for a detailed schedule.

\subsection{ORGANIZATION}

Responsibilities and definitions of organizations for the SNF Project are defined in the overall SNF Project Management Plan (HNF-SD-PMP-011) to which this plan is subordinate. The responsibilities and organizations as they specifically pertain to the STS Subproject are defined below.

\subsection{FLUOR DANIEL HANFORD, INC. (FDH)}

The FDH Project Director, SNF Project, is responsible for the entire SNF Project including the STS Subproject. NHC, as a Major Subcontractor to FDH for the STS Subproject, will report directly to this office for all STS Subproject direction and contract matters.

\subsection{NUMATEC HANFORD CORPORATION (NHC)}

NHC is responsible for all aspects of the STS Subproject scope including process development, design, process equipment acquisition, construction/installation, as-built facility documentation, procedures, and documentation supporting startup and operations. NHC has authority to develop and control the subproject baseline and performance measures (within established limits), to procure facilities and systems necessary to complete the subproject, and to exercise design authority for facilities and systems.

NHC will assign an STS Project Manager reporting to the NHC SNF Conditioning Projects Director. The STS Project Manager has the final responsibility for meeting the cost, schedule 
and technical objectives for the STS Subproject. The Project Manager is the primary individual who will represent the project to FDH and is accountable for cost and schedule performance. The project organization for the project definition phases of the project is shown in Figure 4. It is anticipated that the organization will evolve to include different functions as the project progresses. Matrix support will be provided to the Project Manager by other organizations (e.g. engineering, project controls, scheduling, cost estimating, procurement and quality assurance).

An Engineering Lead will be assigned from NHC Engineering who will be responsible for all technical aspects of the project. With NHC's technical management approach, safety and environmental technical documentation are prepared as part of the engineering process and, therefore, will also be under the management of the Engineering Lead to assure all technical aspects of the project are well coordinated. The Engineering Lead will also be responsible for coordination of technical interfaces with entities outside the project such as the SNF Project, TWRS and the Solid Waste Disposal Program.

During the Concept Definition phase, NHC will supplement its staff with resources from Fluor Daniel Northwest (FDNW), SGN Eurisys Services Corporation (SEC.) and other contractors if necessary. We will use SGN corporate resources for selected tasks. NHC will obtain laboratory/testing services from 222-S Laboratory and/or Pacific Northwest National Laboratory (Pacific Northwest) and the Project Hanford Management Contract (PHMC) Engineering Laboratory.

\subsection{DE\&S HANFORD, INC. (DESH)}

DESH is responsible to FDH for the remainder of the SNF Project and is responsible for operation of the K Basin. The DESH interface with the STS Subproject will be for coordination of utility infrastructure support in $100 \mathrm{~K}$ Area and retrieval of the sludge from the basins. DESH will provide permitting and regulatory support for this subproject under NHC direction for $100 \mathrm{~K}$ area activities.

\subsection{FLUOR DANIEL NORTHWEST, INC (FDNW)}

FDNW will be provided task orders to supply Architectural-Engineering/Construction Management (A-E/CM) staff to support NHC for the Concept Definition phase of the project. Discrete A-E/CM scopes of work may be assigned to FDNW in later stages of the project.

\subsection{SGN EURISYS SERVICES CORPORATION (SEC.)}


SEC. will be provided task orders to supply specialty engineering staff to support NHC for the Concept Definition phase of the project. Discrete scopes of work may be assigned to SEC. in later stages of the project.

\subsection{PROJECT MANAGEMENT AND CONTROL}

The project will be managed in compliance with the SNF Project Management Plan (HNF-SDSNF-PMP-011) and its subordinate topical plans. The basic principles to be implemented include development of a sound cost, schedule, and technical baseline and a formal work authorization and control system. This approach includes timely and accurate status of work. performance with appropriate management reports, reviews and actions to assure timely resolution of issues and to maintain integrity of the baselines.

A Work Breakdown Structure (WBS) for the overall subproject is shown in Figure 5 and a WBS dictionary is provided in Appendix D. This structure is preliminary and will be developed further as part of the project baseline development. A WBS for the project definition phases is shown in Figure 6 and the cost estimate, schedule and list of deliverables are consistent with this WBS.

Figure 7 shows how the technical baseline develops through the life of the project, beginning with top level requirements from the SNF Project and TWRS, and evolving as the project matures. From the products developed during the project definition phase, certain documents will be extracted and integrated into a project baseline FDC which will control the project during its entire life. As the project proceeds to each subsequent phase, more detailed documents will be extracted from the products as they are developed and will be placed under baseline control to guide the next phase. Each of these documents must be consistent with the FDC.

Figure 8 graphically shows how the near term products developed in the project definition phases are integrated into the functional design criteria (FDC), process flow diagram (PFD), and interface control documents (ICD) to form the technical baseline. Figure 8 also shows the development of the cost and schedule baselines as well as the management documents that will be used to control the project.

The baseline will be reflected in an updated PEP which will include how we will control the baseline (including appropriate control thresholds), and implement performance measures, monitoring, and reporting. Configuration management and interface control will also be addressed to assure that interfaces and requirements from SNF, TWRS and the Solid Waste Program are understood and controlled. Interface control is critical to the project with the 
changing technical requirements that inevitably evolve from programmatic, safety and environmental origins.

Testing activities will be performed to approved test plans which include acceptance criteria.

Figure 9 provides a preliminary document approval matrix for the project. Those documents prepared after the completion of baseline definition are marked, "to be determined (TBD)," pending completion of the updated PEP.

For the project definition phases we will use existing site-wide systems to control and monitor the project. The existing system will be used to track and produce earned value reports to the second level of the WBS (e.g., concept definition) on a monthly basis. We also will monitor and status the schedule in percent complete on a monthly basis. These will be inciuded in a monthly report submitted to FDH.

\subsection{ACQUISITION STRATEGY}

For the Concept Definition phase, only staff support task orders to FDNW, SEC. and possibly other subcontractors are expected to be placed. A preliminary project execution strategy will be developed which will consider innovative contracting options for the Baseline Definition phase as well as the project execution phase (design, procurement and installation of the system). The plan for the Baseline Definition phase may need to be revised based on the recommendations in the strategy.

The acquisition options for project execution could range from a conventional project with a definitive design prepared by FDNW followed by fixed-price fabrication and installation, to a fast track project with concurrent development, engineering and fabrication and cost type installation. We will also consider producing a performance specification for a complete turnkey system with the vendor designing, fabricating, installing and perhaps operating the system. In all options we will look at applying appropriate incentives to assure a quality, timely and cost effective solution is developed. The acquisition strategy chosen will be documented as part of the Baseline Definition phase.

\subsection{SAFETY STRATEGY}

Major potential safety concerns are associated with several steps of the treatment: 
- criticality of the untreated sludge

- chemical reactivity of the untreated sludge

These uncertainties induce a high level of risk for the project if these issues are not addressed early in the project life. A proactive safety strategy has been defined; the initial elements are outlined in Appendix B. The main features of this strategy are:

- assignment of an Engineering Lead inside the project who is responsible for all design, including safety documentation.

- a safety assessment carried out during the Concept Definition phase. This early involvement of safety in the concept selection will avoid developing a design that cannot be supported by a SAR.

- a PHA / PSE developed during conceptual design with a design where the major technical choices (type of process / type of equipment) have been made.

- the inclusion of the as low as reasonably achievable (ALARA) principle early in the design activities with shielding, operations and maintainability studies done in the concept selection phase. This will support initial design decisions to be made considering ALARA principles. The detailed ALARA analysis planned during the definitive design phase will build on these early ALARA analyses.

Figure 7, which shows the technical baseline evolution over the project life, assumes a conventional DOE SAR development process with a PSE/PSAR/FSAR document sequence. We intend to discuss this development process with FDH during the Concept Definition phase to consider combining the PSE/PSAR into one document.

\subsection{ENVIRONMENTAL/REGULATORY STRATEGY}

This project has significant environmental and regulatory issues which must be resolved as part of the design of the process system. The sludges contain PCB regulated under the Toxic Substances Control Act (TSCA) and have both hazardous and radionuclide content which make them subject to mixed waste criteria. A preliminary environmental strategy will be developed during the Concept Definition phase to address these issues. Significant interaction with the regulators in the course of design evolution is expected. 
FIGURE 1. SLUDGE TREATMENT SYSTEM

\begin{tabular}{|c|c|c|c|c|c|c|c|c|c|c|c|c|c|c|c|c|c|}
\hline \multirow[b]{2}{*}{$1 \mathrm{D}$} & \multirow[b]{2}{*}{ Task Name } & \multicolumn{12}{|c|}{1998} & \multirow[b]{2}{*}{ J } & \multirow[b]{2}{*}{$F$} & \multirow[b]{2}{*}{$M$} & \multirow[b]{2}{*}{$A$} \\
\hline & & $\mathrm{J}$ & $F$ & $M$ & A & $M$ & $\mathrm{~J}$ & $\mathrm{j}$ & A & $s$ & 0 & $\bar{N}$ & D & & & & \\
\hline 1 & Project Definition & & & & & & & & & & & & & & & & \\
\hline 2 & FDH letter & & $2 / 3$ & & & & & & & & & & & & & & \\
\hline 3 & Concept definition & & & & & & & & & & & & & & & & \\
\hline 4 & Proj.Basis rev A & & & & & & & & & & & & & & & & \\
\hline 9 & Process Studies & & & & & & & & & & & & & & & & \\
\hline 21 & Safety Studies & & & & & & & & & & & & & & & & \\
\hline 30 & Transport & & & & & & & & & & & & & & & & \\
\hline 32 & O\&M Concept & & & & & & & & & & & & & & & & \\
\hline 34 & Site selection & & & & & & & & & & & & & & & & ' \\
\hline 36 & Laboratory Testing & & & & & & & & & & & & & & & & \\
\hline 42 & Interface Requirements & & & & & & & & & & & & & & & & \\
\hline 45 & Proj.Basis rev B & & & & & & & & & & & & & & & & \\
\hline 53 & Project documentation & & & & & & & & & & & & & & & & \\
\hline 58 & Review & & & & & & & & & & & & & & & & \\
\hline 60 & Project Management and Support & & & & & & & & & & & . & & & & & \\
\hline 67 & Decision to continue & & & & & & & & $8 / 5$ & & & & & & & & \\
\hline 68 & Baseline definition & & & & & & & & & & & & & & & & \\
\hline 69 & Engineering studies & & & & & & & & & & & & & & & & \\
\hline 77 & PHAIPSE & & & & & & & & & & & & & & & & \\
\hline 81 & Proof of Principle Tests & & & & & & & & & & & & & & & & \\
\hline 89 & Project Basis rev $C$ & & & & & & & & & & & & & & & & \\
\hline 95 & Project documentation & & & & & & & & & & & & & & & & \\
\hline 100 & Submit project baseline & & & & & & & & & & & & & & & 118 & \\
\hline 101 & Reviews & & & & & & & & & & & & & & & & \\
\hline 105 & Approved project baseline & & & & & & & & & & & & & & & & $4 / 2$ \\
\hline 106 & Project Management and Support & & & & & & & & & & & & & & & & \\
\hline
\end{tabular}


Figure 2. Summary Cost Estimate

SLUDGE TREATMENT PROJECT

Project Definition

\begin{tabular}{|c|c|c|c|}
\hline WBS & Tasks & Cost $(\$)$ & Cost with G\&A (18\%) \\
\hline 1.0 & Concept Definition & & \\
\hline 1.1 & Project Basis Rev. 0 & 89,000 & \\
\hline 1.2 & Process studies & 198,000 & \\
\hline 1.3 & Safety studies & 232,000 & \\
\hline 1.4 & Transport & 19,000 & \\
\hline 1.5 & O\&M Concept & 16,000 & \\
\hline 1.6 & Site selection & 78,000 & \\
\hline 1.7 & Laboratory testing & 830,000 & \\
\hline 1.8 & Interface Requirements & 146,000 & \\
\hline 1.9 & Project Basis Rev. 1 & 143,000 & \\
\hline 1.10 & Project documentation & 86,000 & \\
\hline 1.11 & Review & 72,000 & \\
\hline \multirow[t]{2}{*}{1.12} & Project Management and Support & 239,000 & \\
\hline & Sub Total & $2,148,000$ & $2,535,000$ \\
\hline 2.0 & Baseline Definition & & \\
\hline 2.1 & Engineering studies & 328,000 & \\
\hline 2.2 & PHA/PSE & 147,000 & \\
\hline 2.3 & Proof of Principle Testing & 314,000 & \\
\hline 2.4 & Project Basis rev 2 & 116,000 & \\
\hline 2.5 & Project documentation & 95,000 & \\
\hline 2.6 & Reviews & 45,000 & \\
\hline \multirow[t]{4}{*}{2.7} & Project management and support & 285,000 & \\
\hline & Contingency $(25 \%)$ & 332,000 & \\
\hline & Sub Total & $1,662,000$ & $1,961,000$ \\
\hline & Total & $3,810,000$ & $4,496,000$ \\
\hline
\end{tabular}




\section{SNF Sludge treatment system}

\section{Staffing profile for project definition phase (FTE)}

Figure 3

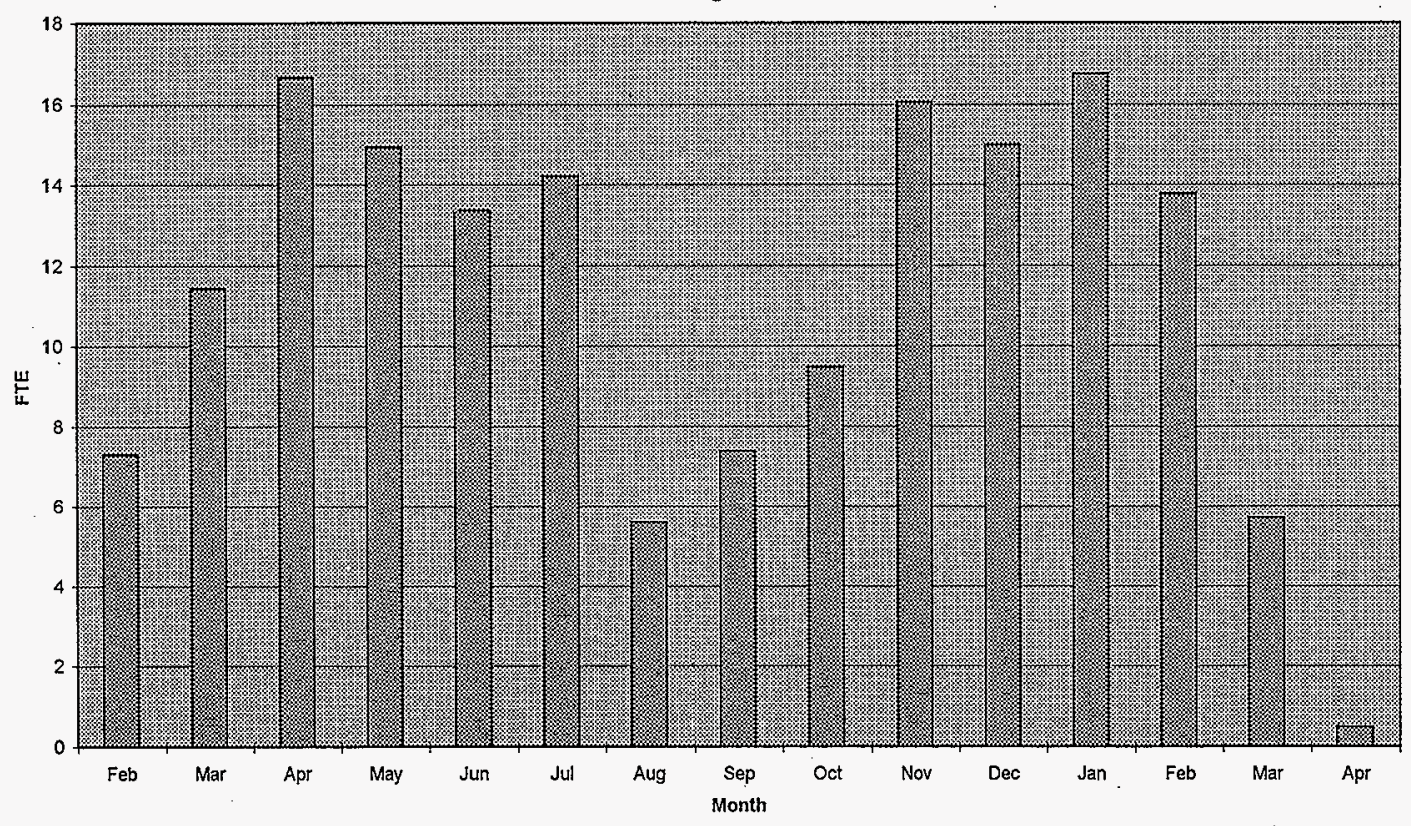


Project Organization for Concept Selection Stage

\section{SNF SLUDGE TREATMENT SYSTEM PROJECT}

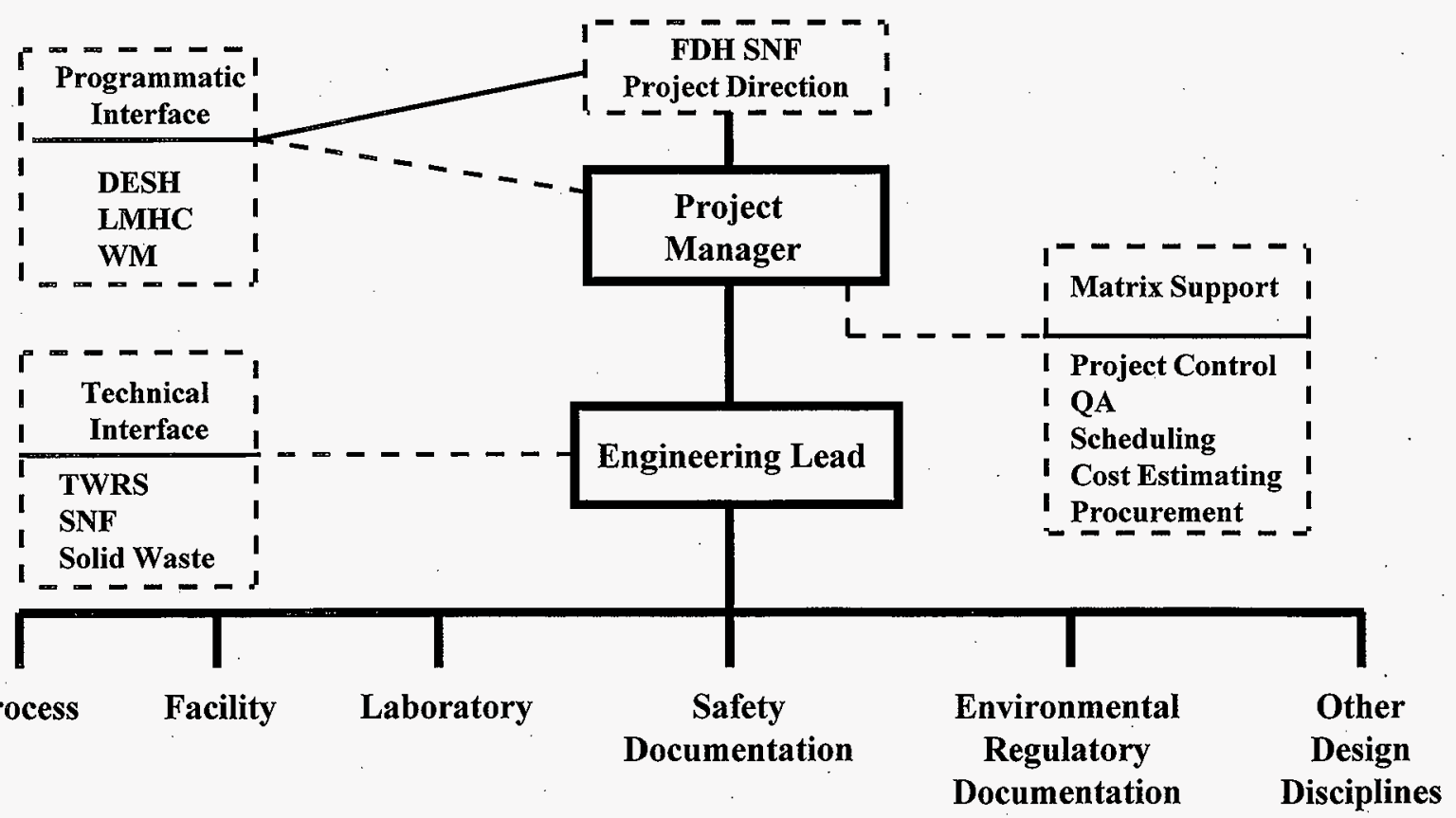

Figure 4. 


\section{WORK BREAKDOWN STRUCTURE}

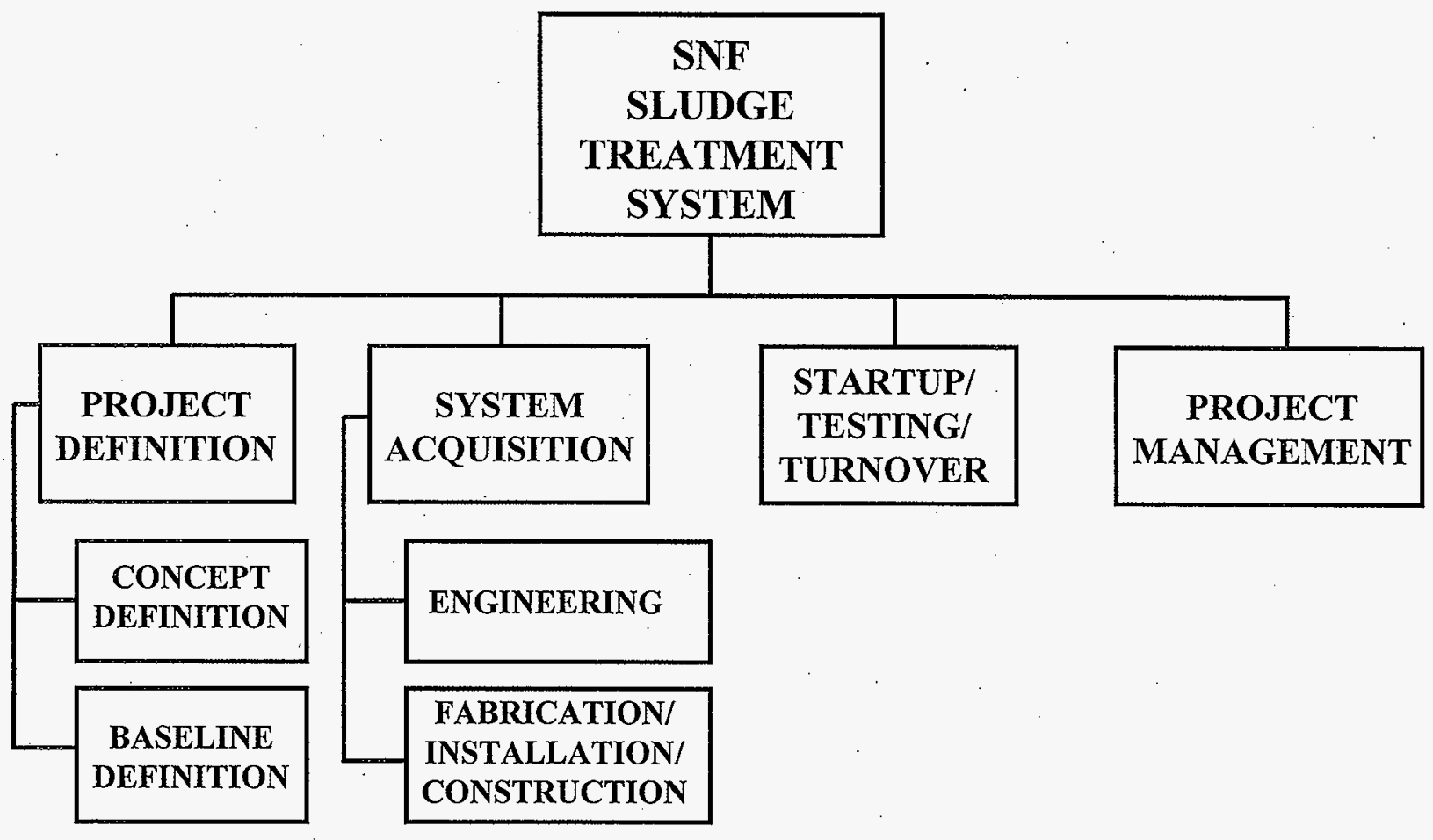

Figure 5. 
SLUDGE TREATMENT SYSTEM (PROJECT DEFINITION PHASE) WORK BREAKDOWN STRUCTURE

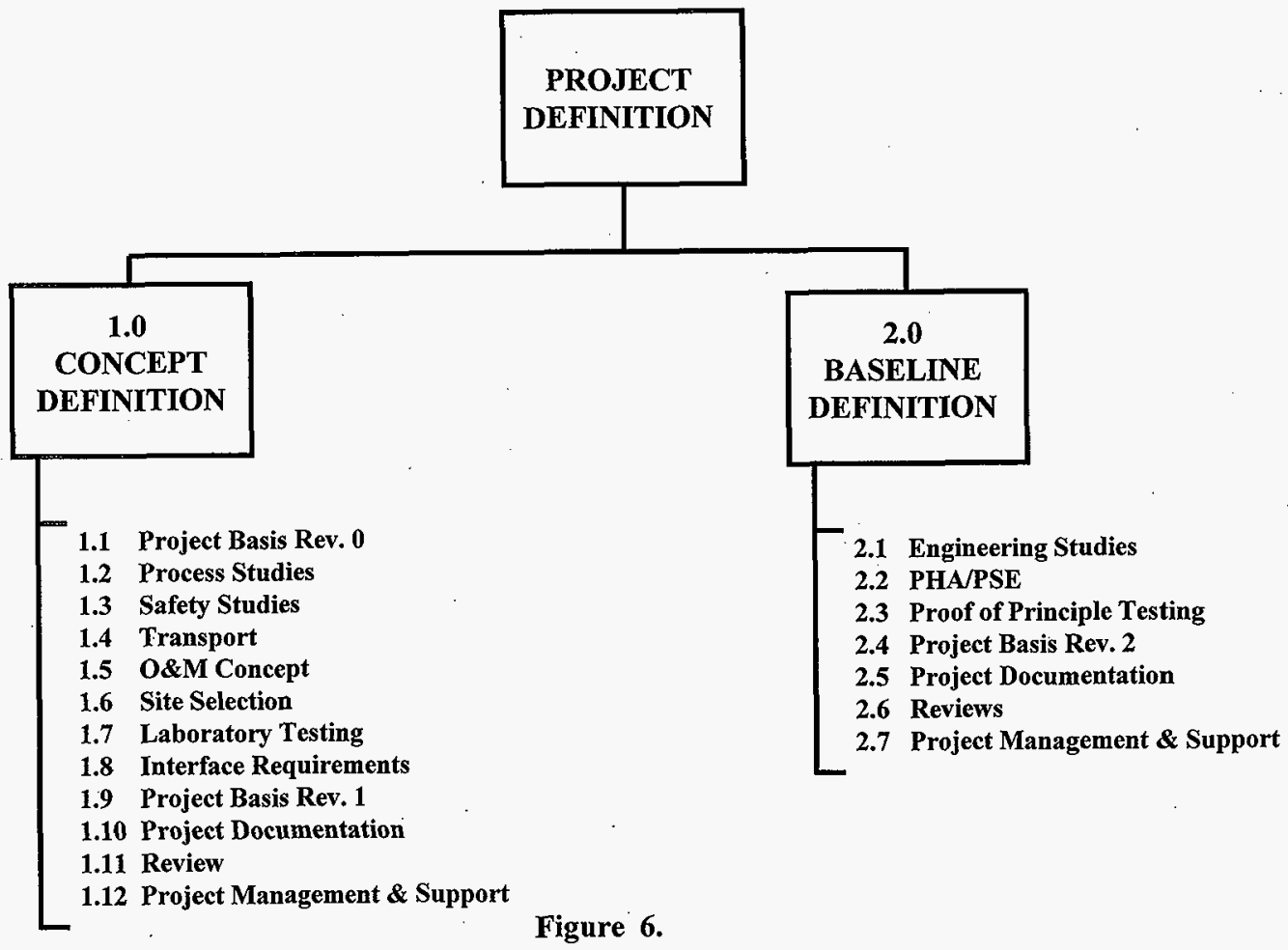




\section{SLUDGE TREATMENT SYSTEM (STS) PROJECT \\ TECHNICAL BASELINE}

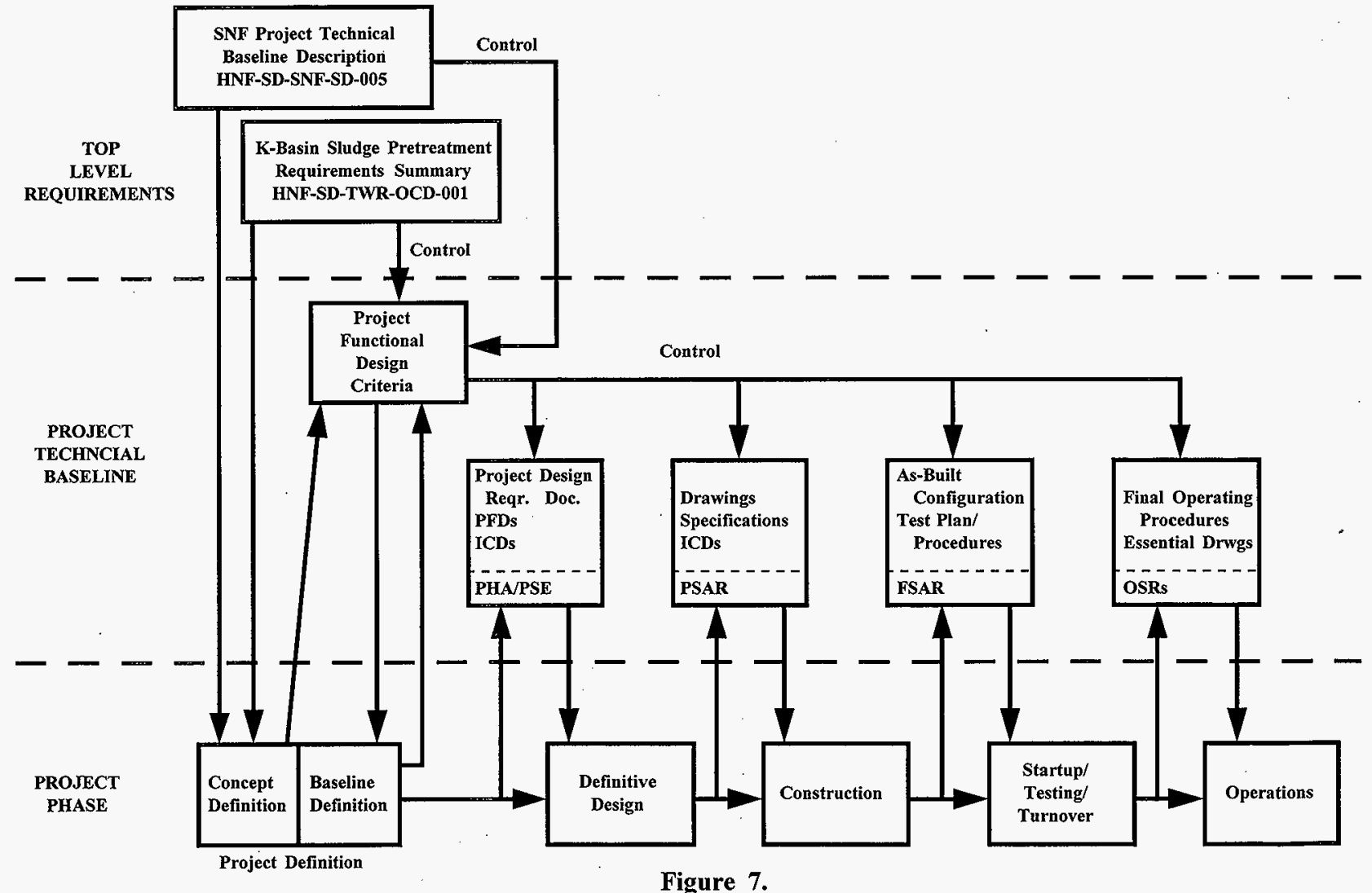




\section{Baseline Development During Project Definition Phase}

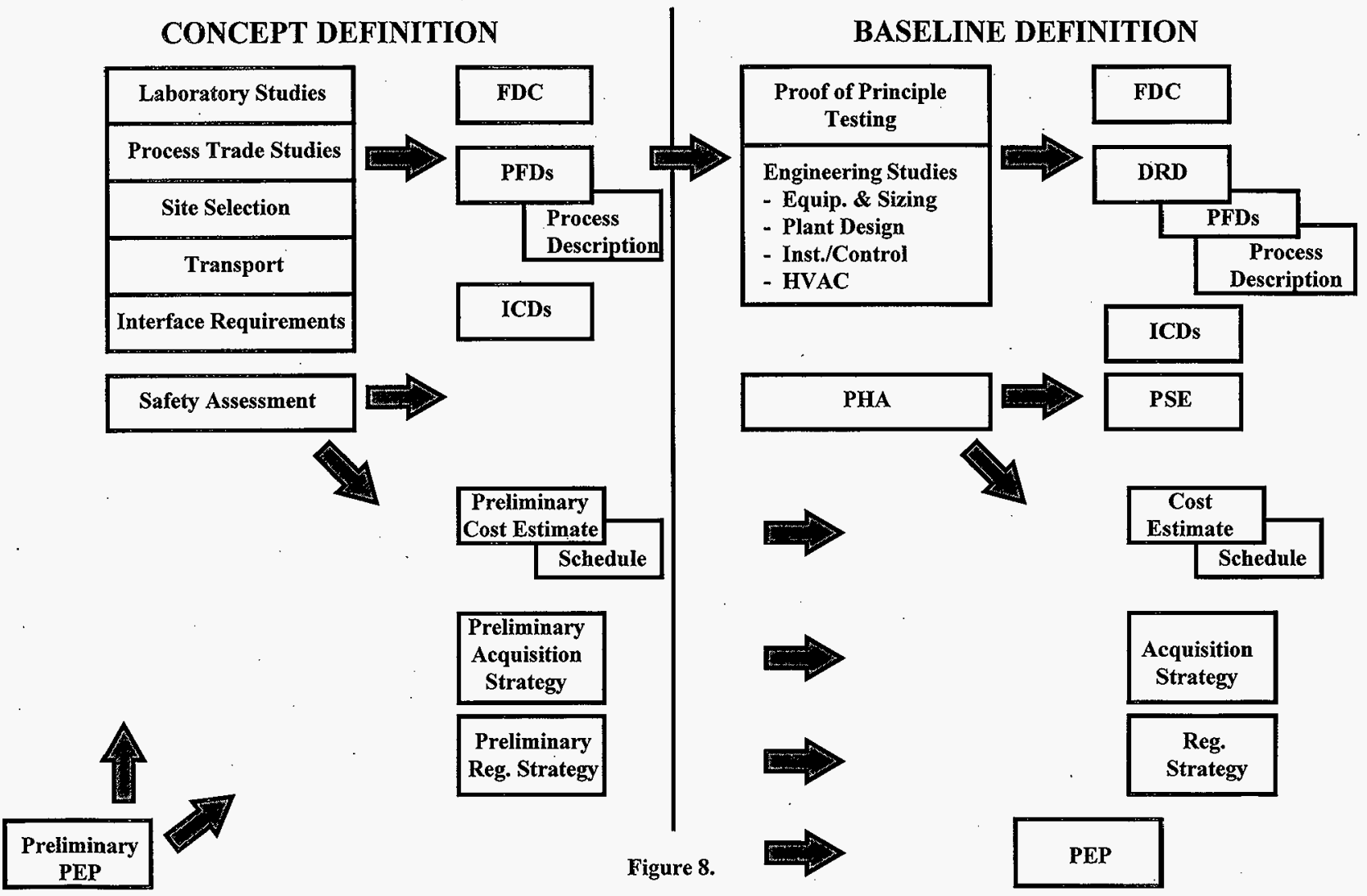




\section{SLUDGE TREATMENT SYSTEM PROJECT \\ DOCUMENT APPROVALS}

\begin{tabular}{|l|c|}
\hline \multicolumn{1}{|c|}{ DOCUMENT } & $\begin{array}{c}\text { APPROVAL } \\
\text { AUTHORITY }\end{array}$ \\
\hline Project Execution Plan & FDH \\
\hline Multi-Year Program Plan & FDH \\
\hline Functional Design Criteria & FDH \\
\hline Preliminary Safety Evaluation & FDH \\
\hline Preliminary Hazards Analysis & NHC \\
\hline Process Flow Diagrams and Descriptions & FDH \\
\hline Design Requirements Document & FDH \\
\hline Process Engineering/Trade Studies & NHC \\
\hline Interface Control Documents (at the sitewide level) & FDH \\
\hline Project Acquisition Plan & FDH \\
\hline Regulatory Strategy & FDH \\
\hline Quality Assurance Plan & FDH \\
\hline Drawings/Specifications & TBD \\
\hline Preliminary Safety Analysis Report & TBD \\
\hline Test and Evaluation Plan & TBD \\
\hline As-Built Drawings & TBD \\
\hline Essential Drawings & TBD \\
\hline Operational Safety Requirements & TBD \\
\hline Operating Procedures & TBD \\
\hline Final Safety Analysis Report & TBD \\
\hline
\end{tabular}

Figure 9 


\section{APPENDIX A}

\section{SNF SLUDGE TREATMENT SYSTEM TECHNICAL UNCERTAINTIES \\ HNF-2281 \\ REVISION 0}


There remain significant technical and safety uncertainties associated with the processing of the $\mathrm{K}$ Basin sludge. These uncertainties span all aspects of the proposed concepts presented in the Preconceptual Design Report. Examples of the uncertainties include:

- the efficiency of the dissolution operation in separating the Polychlorinated Biphenyl (PCB) from the dissolved fraction, and the Transuranic (TRUs) from the non-soluble fraction, is not known, for two reasons:

- available dissolution test results on sludge samples do not include PCB analyses and are too limited on analysis of TRU.

- available sludge characterization results do not include the distribution of PCB and TRU among the different sludge constituents. The main areas of concern are (a) the IX resins, which may have absorbed significant amounts of radionuclides and which will probably not solubilize and (b) the uranium and TRU solids, which may entrain a fraction of the PCB while dissolving.

- Major potential safety concerns are associated with several steps of the treatment:

- $\quad$ criticality of the untreated sludge

- the chemical reactivity of the untreated sludges,

- the runaway reaction risk associated with hot nitric acid dissolution of IX resins

These uncertainties induce a high level of risk for any design activity performed on the proposed treatment. Such risks usually lead to cost increases and missed schedules. Left unresolved, they would raise the contingency range on any cost estimate to unacceptable levels. 
APPENDIX B

SNF SLUDGE TREATMENT SYSTEM TECHNICAL ACTIVITTES AND DELIVERABLES

HNF-2281

Revision 0 
This appendix defines the technical studies and the corresponding documents that will be produced during the "Concept Definition" and "Baseline Definition" phases of the Spent Nuclear Fuel (SNF) Sludge Treatment System Subproject. Items listed in the Baseline Definition Phase are subject to change, pending the decision at the end of the Concept Definition Phase.

\subsection{CONCEPT DEFINITION}

During this phase of the project, the technical baseline of the project will be established. To achieve that goal, a series of studies and tests will be performed and documented dealing with process, safety, mechanical system and facility design.

\section{$1.1 \quad$ PROJECT BASIS}

The project technical basis will be documented in a series of basis documents. These Revision $\mathrm{C}$ documents describe the sludge characteristics, the end-product requirements, the initial process definition and associated Process Flow Diagram (PFD) early in the Sludge Treatment System (STS) project. These Revision C documents will be the reference documents during the concept selection phase. The basis for these documents are the existing published documents at the time of project startup.

\subsubsection{Sludge Data Base}

Defines the characteristics of the sludge to be used in the development of the project. For each value, low, nominal and bounding values will be defined. This document uses existing characterization data and some assumptions when no data are available. The data will include:

- $\quad$ sludge quantities

- sludge chemical composition (elements/compounds)

- $\quad$ sludge radiological composition

- $\quad$ sludge physical characteristics

Defines the requirements for the end products:

- $\quad$ solids 
- treated sludge

- $\quad$ air emissions

- secondary waste (solid/liquid)

Presently, the SNF data book includes only very limited sludge properties. After completion, this Sludge Data Base Revision 0 document will be incorporated in the SNF data book and constitutes the sludge properties chapter.

\subsubsection{Process Description}

This document will provide the technical description of the process. It will:

- describe all the functions of the process including types of functions, process parameters (temp, $\mathrm{pH}$ ), etc. consistent with the PFD

- lists all the assumptions used to establish the process flow diagram

- document all the major uncertainties to be resolved during the concept definition phase.

Each process step will be described in this document.

\subsubsection{Process Flow Diagram}

The PFD will be based on the existing revision of the sludge data base, and on the preliminary process description. It will identify the critical control loops, and will form the basis for the process development.

\subsubsection{Review}

A review using experts from SGN will help Numatec Hanford Corporation (NHC) in the identification of the technical issues to be resolved and recommend the direction to follow to identify existing processes/technologies around the world.

\subsection{PROCESS STUDIES}

The objectives of this set of activities is to define the technologies/processes for the process functions. For each of the technologies/processes, a report will be written to document the findings and recommend a solution. 


\section{Appendix B}

\subsubsection{Dissolution of U/UO2 Mixtures}

The objective of this task is to define the equipment and operating conditions that can handle the sludge (high variation of the U/UO2 ratio, non-soluble content, criticality constraints) and perform the dissolution in a timely manner, without risk of runaway reactions. This task will include:

- Literature survey of the available experience in the United States, Great Britain, France, and Japan

- choice of the dișsolver technology

- choice of the operating parameters

- choice of the control loops

\subsubsection{Solid Liquid Separation}

The main objective of this task is to define a process which will result in a clear liquid and solids that have been washed in a way that minimize radionuclide entrainment with the solids. The task will include:

- literature survey of the available experience in the United States, Great Britain, France, and Japan

- choice of the separator technology

- choice of the operating parameters

- choice of the control loops

\subsubsection{Removal of PCB from HNO3 Solutions}

After the dissolution and separation, a limited quantity of $\mathrm{PCB}$ may be present in the solution. Since the requirement for storage in the tank farms is $\mathrm{PCB}<2 \mathrm{ppm}$ in solids and $\mathrm{PCB}<3 \mathrm{ppb}$ in liquid, a limited literature survey of the available technologies will be done in collaboration with the U.S. Environmental Protection Agency (EPA), the Washington State Department of Ecology and other resources. This survey will assess available technologies used for hazardous waste and evaluate the possibility to implement these technologies on nuclear waste.

\subsubsection{Radionuclide Leaching from the Solids}

After the dissolution and separation, a limited quantity of radionuclides (TRU especially) may be tied to the non-soluble solid. The removal of these radionuclides may be necessary to achieve compliance with the Hanford Solid Waste Acceptance Criteria. A limited literature survey of the 
available technology will be done as soon as the laboratory tests have determined the radionuclide content of the various non-soluble solids. If necessary, a process will be selected to leach the radionuclides from the solids.

\subsubsection{Precipitation of Uranium}

Uranium contained in the liquid solution will be coprecipitated with a depleted uranyl nitrate solution (for isotopic dilution) by addition of caustic soda. The two objectives are to obtain good mixing of enriched and depleted solution and to obtain a precipitate particle size lower that 10 microns to meet tank farm criticality requirements. The document will include:

- literature survey of the available experience in the United States, Great Britain, France, and Japan

- choice of the precipitator technology

- choice of the operating parameters

- choice of the control loops

\subsubsection{Liquid/Solid Transfer}

The solid content in solution will be high at several steps of the process. In order to facilitate the maintenance of the processing units, it is essential to select technologies (transfer devices, valves, flow meters) that comply with the following criteria:

- low risk of solid retention

- reliability

The task will include :

- literature survey of the available experience in the United States, Great Britain, France, and Japan

- choice of the technologies

- choice of the operating parameters

- choice of the control.loops

\subsubsection{Flotation Study}

Organic ion exchange resins have been identified as a minor component in the sludge. However, even in small quantities, they can have detrimental consequences in the following areas: 


\section{Appendix B}

- $\quad$ safety of the dissolution process step due to the possible reactions between $\mathrm{HNO} 3$ and the resins

- $\quad$ entrainment of radionuclides (TRU, Cs) within the non-soluble solids which could jeopardize meeting the mixed waste requirements for storage in ERDF

Since the resins have a low density, flotation technologies (with or without flotation agent) or "elutriation" technologies may be applied to separate these before or after the dissolution process.

This study will include:

- literature survey of the available experience in the United States, Great Britain, France, and Japan

- $\quad$ choice of separation technology (use of flotation agent will be considered)

- $\quad$ choice of the operating parameters

- choice of the control loops

\subsubsection{Safeguards}

We will consult B\&W Protec, Inc. (BWP) to establish the appropriate constraints for Special Nuclear Materials (SNM). The main objective is to define the constraints that may impact the design of the processing unit, including:

- batch size

- type of control for the fissile material

- transport /transfer

- $\quad$ accountability facility/process steps

\subsubsection{Removal of PCB from Solids}

After the dissolution and separation, the bulk of the PCB will be in the non-soluble solids. The removal of this PCB will be necessary only if these solids do not meet the Hanford Solid Waste Acceptance Criteria. A limited survey of the available technology will be done in collaboration with EPA, the Washington State Department of Ecology, and other resources.

\subsubsection{Solid Conditioning}

The conditioning of the PCB-contaminated solids ( $\mathrm{PCB}$ product) is not included in the scope of the project. A limited survey of the existing solid conditioning technologies on the site will be 
SNF Sludge Treatment System

Rev. 0

Technical Activities and Deliverables

HNF-2281 Appendix B

performed. Special emphasis will be given to the technology used for the conditioning of the $\mathrm{N}$ Reactor basin sludge. The interface between the sludge chemical processing unit and the conditioning unit will be defined.

\subsubsection{Dissolver Off-Gas}

The off-gas treatment unit will purify the dissolver off-gas in order to comply with the current stack release requirements. Additional constraints for this unit are:

- variation of the $\mathrm{NOx}$ composition with $\mathrm{U} / \mathrm{UO} 2$ ratio and $\mathrm{HNO} 3$ acidity

- $\quad$ presence of $\mathrm{H} 2$ in the off gas

- $\quad$ presence of $\mathrm{PCB}$

This task will include:

- literature survey of available NOx removal experience in the United States, Great Britain, France, and Japan

- removal of PCB from the off gas

- $\quad$ evaluation of the radionuclides that may volatize $(\mathrm{I}, \mathrm{H} 3 \ldots)$

- choice of the necessary off gas functions and technologies

- $\quad$ choice of the operating parameters

- choice of the control loops

\subsection{SAFETY STUDIES}

During the concept definition phase this task will include:

- define the safety requirements for the design of the transport of the sludge (K Basin to the facility, facility to Tank Farms) and the chemical processing

- prepare supporting documentation for the safety document (PHA/PSE) that will be completed in the baseline definition phase

To achieve these goals, the following documents will be prepared:

\subsubsection{Shielding Calculation for the Transport}

Rough estimate of shielding needs during loading, unloading of the cask, maintenance and 
transport.

\subsubsection{Preliminary Criticality Calculation for the Transport}

Evaluation of maximum quantities/volume/geometry.

\subsubsection{Chemical Reaction Model for the Transport}

Modeling of the reactions (water with uranium or water with uranium hydride) that can occur in the transport cask. The issues that have to be addressed are:

- heat release

- hydrogen production

- over pressurization

\subsubsection{Safety Assessment of the Transport}

The objective of this document is to define the safety requirements that have to be used for the selection of the transfer system. This document will include:

- hazardous materials inventory

- confinement analysis for different steps of the transport (loading, unloading, maintenance)

- $\quad$ radiation protection analysis

- criticality

- chemical reaction (heat generation and gaseous release)

- radiolysis analysis

- $\quad$ internal and external risks (fire, explosion, drop/impact, Natural Phenomena Hazards (NPH))

- $\quad$ safety requirements summary

\subsubsection{Shielding Calculation for the Processing Units}

Rough estimate of shielding needs during loading, unloading of the cask, and maintenance.

\subsubsection{Preliminary Criticality Calculation for the Processing Unit}

Evaluation of maximum quantities/volume/geometry for the various processing units of the project. 
Appendix B

\subsubsection{Chemical Reaction Model for the Processing Units}

Modeling of chemical reactions that can occur at the various steps of the process. The following reactions have to be considered:

- U/UO2 with nitric acid at various temperature and concentrations

- Organic ion exchange resins with nitric acid

The following issues have to be addressed:

- heat release

- hydrogen production

- over pressurization

\subsubsection{Safety Assessment}

The objective of this document is to define the safety requirements that have to be used for:

- the concept selection (process/technologies)

- the site/facility selection

This document will include:

- hazardous materials inventory

- confinement analysis for different steps of the process and during maintenance operations

- $\quad$ radiation protection analysis

- criticality

- chemical reaction (heat generation and gaseous release)

- radiolysis analysis

- internal and external risks (fire, explosion, drop/impact, NPH)

- $\quad$ As low as reasonably achievable (ALARA) preliminary approach

- $\quad$ safety requirements summary

\subsection{TRANSPORT}

This study will be dedicated to the evaluation of the various alternatives for the transport of the sludge from the $\mathrm{K}$ Basins to the processing facility and from the facility to Tank Farms. This 
study will take into account the safety requirements established by the safety team. In a first step, the existing transport technologies (especially LR56) and the technology designed by the DE\&S Hanford, Inc. (DESH) Project will be evaluated. If they don't fulfill the requirements, a . limited design effort for a new system will be initiated in order to support the transport evaluation step in the site selection study.

\subsection{OPERATION/MAINTENANCE CONCEPT}

This study includes:

- $\quad$ the definition of the equipment that may require maintenance (pump, valves)

- the definition of the maintenance concept for the equipment requiring maintenance during the lifetime of the facility

- the identification of equipment which reliability has to be improved to optimize the lifecycle cost

- the definition of the operation concept

\subsection{SITE SELECTION}

The purpose of this activity is to analyze various site possibilities (about 4) and select the best one for the processing facility. For each candidate site, the alternative study will consists of:

\subsubsection{Preliminary Layout Drawings}

These drawings will define the location of the facility within the site, and the arrangement and the location of the main equipment in order to show the volume occupied by the process (process and mechanical systems), and identify the main existing or additional systems to be implemented or modified.

\subsubsection{Transfer Studies}

According to site location, transfer means can differ. This section will explain, through sketches and descriptions, the most suitable transfer systems to be provided.

\subsubsection{Available Utility Evaluation}

Based on process operation needs, each site will be evaluated to identify the available utilities 
and/or utility systems to be added. This includes power, water, effluent treatment or discharge, gas, chemicals, Heating, Ventilating, and air conditioning (HVAC), etc.

\subsubsection{Facility Description}

The purpose of this document will be to support the layout drawings with additional description of the installation and to summarize the surveys made to evaluate the different facilities. Main advantages, drawbacks, and issues of each site alternative will be compared for the following criteria:

- available space

- $\quad$ available utilities

- additional systems and/or system to be modified

- safety

- environmental and permitting requirements

- construction

- personnel access

- operation and maintenance

- cost

The conclusion of the document is the selection of one site.

\subsection{LABORATORY TESTING}

Laboratory testing will be performed to an approved test plan with appropriate test acceptance criteria. The main issues addressed by the laboratory testing are:

- possibility to separate the organic ion exchange resin from the sludge (cold testing)

- reaction between nitric acid and ion exchange resin creating potential reactive compounds (cold testing)

- condition of dissolution to be used to optimize the dissolution of the sludge (hot testing)

- $\quad$ partition of PCB and radionuclides after the dissolution step (hot testing)

- possibility to leach radionuclides from the solids (hot testing)

To address these issues, the available quantity of sludge that has been sampled from the $\mathrm{K}$ Basins and are currently stored in Pacific Northwest National Laboratory (Pacific Northwest) 
SNF Sludge Treatment System

Rev. 0

Technical Activities and Deliverables

HNF-2281

Appendix B

labs appears to be sufficient. Limited cold testing will be necessary to support the flotation study.

\subsection{INTERFACES REQURREMENTS}

\subsection{TWRS Interface Requirements}

To better define the TWRS requirements to accept the product coming from the processing facility, the following tasks will be performed:

- Definition of the depleted uranium and iron oxide requirements for safely storing the $\mathrm{K}$ Basin sludge in 241-AW-105.

- $\quad$ Prepare the schedule and budget for TWRS authorization basis related activities in support of the $\mathrm{K}$ Basin sludge removal project. This task will include all safety related issues, including criticality.

- Develop strategy and approach for revision of the TWRS source term document.

- Issue Criticality Safety Evaluation Report (CSER) for storage of K Basin sludge in 241-AW-105.

- $\quad$ Prepare Amendment Task Plan for revising the Authorization Basis to enable TWRS acceptance of $\mathrm{K}$ Basin sludge. That plan lists all actions required for the implementation of the amendment, the responsible organization and the schedule to complete the action.

\subsubsection{Environmental Restoration Disposal Facility Interface Requirements}

Discussions will be held between the project and Environmental Restoration Disposal Facility in order to define the product specification of the solid end product. In order to foster the process, the lessons learned from the Bechtel experience for the acceptance criteria for the $\mathrm{N}$ Basin sludge will be the basis for the development of the acceptance criteria for the solids separated in the sludge processing facility.

\subsection{PROJECT BASIS}

The objective in this task is to update the PFDs and their supporting documentation and to prepare the Functional Design Criteria (FDC). These documents will be a synthesis of all the documents established during the "concept selection phase" (process studies, safety studies, site selection). A preliminary Interface Control Document will be also prepared. 


\subsubsection{Sludge Data Base}

Defines the characteristics of the sludge to be used. For each value low, nominal and bounding value will be defined. The revision 0 document will be updated based on laboratory test data. Key sludge parameters include:

- $\quad$ sludge quantities

- $\quad$ sludge chemical composition (element / compounds)

- sludge radiological composition

- $\quad$ sludge physical characteristics

Defines the requirements for the end products:

- $\quad$ solids

- treated sludge

- air emission

- $\quad$ secondary waste (solid/liquid)

\subsubsection{Process Description}

This document integrates the results of all the process studies. It incudes:

- preliminary block diagram

- preliminary mass balance

- definition of technologies and operating parameters (batch size, temperature, $\mathrm{HNO} 3$ concentration)

- preliminary equipment list

- preliminary utility balance

\subsubsection{Process Flow Diagram}

Update the PFD based on:

- $\quad$ sludge data base revision 1 and Process description revision 1

- $\quad$ adding critical control loops

\subsubsection{Functional Design Criteria}

The result of all the studies carried out in the "concept selection phase" will be used to establish 
an FDC which will define high-level functions and requirements for the project.

\subsubsection{Mechanical System}

An analysis of the mechanical functions implemented in the processing facility will be done. For the most complex ones, implementation options will be proposed and studies will be prepared to solve major uncertainties.

\subsubsection{Identification of Cold Testing Needs}

During the studies carried out previously, uncertainties may be identified for some process steps. These uncertainties will be identified in this document, as well as the cold test program to resolve these issues.

\subsubsection{Preliminary Interface Control Documents}

Preliminary Interface Control Documents will be prepared to describe the interfaces of the project with Tank Waste Remediation System (TWRS), Sludge removal project, Sludge transportation project and the Solid Waste Disposal facility. These documents will define the interface requirements taking into account the end product requirements and the studies done during the concept phase definition (transport, safety assessment, site selection...). These documents will also address how these interfaces can be modified or adapted to changes of the technical requirements.

\subsection{PROJECT DOCUMENTATION}

The objective of this task is to prepare the preliminary project acquisition strategy and regulatory strategy and to prepare and document the preliminary cost estimate and schedule for the entire project. The plan for the Baseline Definition phase will be updated as necessary.

\subsection{REVIEW}

A senior review of the project documentation will be undertaken at the end of the Concept Definition phase. The subject of the review will be:

- assessment of the technical choice (process, site, safety...)

- assessment of the acquisition strategy 
SNF Sludge Treatment System

Rev. 0

Technical Activities and Deliverables

Appendix B

HNF-2281

- assessment of the regulatory strategy

The outcome of that review is the decision to proceed or not with the proposed project strategy and choices.

\subsection{PROJECT MANAGEMENT AND SUPPORT}

This task provides the level of effort support for a full time project manager and secretary and part time support for project controls and quality assurance. 


\subsection{BASELINE DEFINITION}

This phase will establish the documentation necessary to initiate the Definition Design of the processing facility. This information is subject to change pending the decision at the end of the Process Definition phase of the project.

\subsection{ENGINEERING STUDIES}

\subsubsection{Definition of the Process Equipment}

During this phase, a list of the main equipment will be established. For all the process equipment, the following information will be given:

- Preliminary sketch to identify:

- size

- shape

- material for construction

- instrumentation

\subsubsection{Instrumentation / Control}

The following documents will be issued:

\section{I\&C System Description}

The purpose will be to identify and describe the Instrumentation and Control (I\&C) system, including the operating principles and the main design rules. It includes an I\&C architectural diagram which is a schematic representation of the control and monitoring process from the sensors/actuators level to the control level. 


\section{Main Instrumentation Preliminary Data Sheet}

The purpose is to identify process requirements for instrumentation and to indicate the type and main characteristics of selected instrumentation.

\subsubsection{Plant Design}

The following documentation will be developed and issued:

- General Arrangement Drawing

This drawing serves to define the arrangement and sizing of the main equipment and to demonstrate the feasibility of the transfer systems. It also provides a better understanding of the mechanical process through a simplified graphic overview.

\section{- Preliminary Pump Specification}

Studies will be performed on transfer systems to evaluate main pump characteristics.

- Site Layout, Facility Layout, Facility Description

The documents produced for site selection will be revised to include details developed during Conceptual Design. The utilities ( compressed air, inert gas, water...) balance and heat load will be updated.

\subsubsection{Mechanical System}

In this phase, the mechanical systems identified in Section 1.5 will be studied and for each system, an implementation approach (principle, material to be used, sketches) will be established.

For each of the mechanical systems, the maintenance will be defined and spare parts will be recommended.

\subsubsection{Heating, Ventilating, and Air Conditioning}

\section{- Building Ventilation Description}

This describes the ventilation requirements, the ventilation system and the principles of its 
operation.

\section{- Ventilation Flow Diagram}

This shows the main process data of the ventilation system in a schematic manner and the various subsystems and treatment units which provide the ventilation functions.

\subsubsection{Electrical systems}

This phase will result in the issuance of the following electrical system documents:

- Power Balance

The purpose is to identify the electrical power requirements of the installation. It will be used to evaluate the available power and/or to size the additional electrical equipment required. (Characteristics of additional equipment will be identified in the main equipment list).

- Single Line Electrical Diagram

The purpose is to describe the architecture of the electrical distribution system and its connection with existing systems.

\subsection{PHA /PSE}

The content of the Preliminary Safety Evaluation (PSE) is defined in the HNF-PRO-703, Revision 0, Appendix A.

In order to finalize a PSE, a Preliminary Hazards Analysis (PHA) will be developed by a multi disciplinary team.

\subsection{PROOF OF PRINCIPLE}

This testing phase is currently planned in our schedule, cost, and deliverable list but will only be implemented if justified by technical uncertainties for certain technologies or set of technologies. If so, the deliverables will be:

- Test plan including the definition of the test acceptance criteria 
- Reports documenting the results of the tests

- Incorporation of the selected/qualified implementation options in the Conceptual Design

\section{$2.4 \quad$ PROJECT BASIS}

All the documentation established in the previous phase will be gathered and the project baseline will be established using these documents and the project strategy, including the cost and schedule to completion.

\subsubsection{Sludge Data Base}

Defines the characteristics of the sludge to be used. For each value low, nominal and bounding value will be defined. The revision 1 document will be updated based on laboratory test data.

Key sludge parameters include:

- $\quad$ sludge quantities

- $\quad$ sludge chemical composition (element / compounds)

- $\quad$ sludge radiological composition

- $\quad$ sludge physical characteristics

Defines the requirements for the end products:

- $\quad$ solids

- treated sludge

- air emission

- $\quad$ secondary waste (solid/liquid)

\subsubsection{Process Description}

This document integrates the results of all the process studies. It includes:

- block diagram

- mass balance

- definition of technologies and operating parameters (batch size, temperature, $\mathrm{HNO} 3$ concentration)

- $\quad$ sizing of the equipment 


\section{Appendix B}

- $\quad$ equipment list
utility balance

\subsubsection{Process Flow Diagram}

Update the PFD based on:

- $\quad$ sludge data base revision 2 and Process description revision 2

- $\quad$ adding critical control loops

\subsubsection{Final Interface Control Documents}

The Preliminary Interface Control Documents established at the end of the Concept Definition Phase will be updated in order to have clear interface before the beginning of the definite design phase.

\subsubsection{Design Requirement Document (DRD)}

The technical requirements for the definitive design phase will be gathered in a DRD. These will be consistent with, but more detailed than, the FDC to provide definitive direction to the system designer on a system basis. This document also addresses the design requirements for normal, off-normal, upset and faulted conditions.

\subsection{PROJECT DOCUMENTATION}

This task prepares an updated project acquisition strategy and an updated regulatory strategy. It also develops the final project cost estimate and schedule to be included as part of the project baseline. An updated Project Execution Plan and a quality assurance plan will also be produced.

\subsection{REVHEWS}

Reviews of the conceptual design package will be done by Fluor Daniel Hanford (FDH) and the U.S. Department of Energy, Richland Operation Office (RL) and the comments will be incorporated in the final conceptual design package.

\subsection{PROJECT MANAGEMENT AND SUPPORT}

This task provides the level of effort support for a full time project manager and secretary and part time support for project controls and quality assurance personnel. 


\section{APPENDIX C \\ SNF SLUDGE TREATMENT SYSTEM \\ DETAILED SCHEDULE}

HNF-2281

Revision 0

$c-i$ 


\section{SLUDGE TREATMENT SYSTEM}

\begin{tabular}{|c|c|c|c|c|c|c|c|c|c|c|c|c|c|c|c|c|c|}
\hline \multirow[b]{2}{*}{ ID } & \multirow[b]{2}{*}{ Task Name } & \multicolumn{12}{|c|}{1998} & \multirow[b]{2}{*}{$\bar{J}$} & \multirow[b]{2}{*}{$\mathrm{F}$} & \multirow[b]{2}{*}{$M$} & \multirow[b]{2}{*}{ A } \\
\hline & & 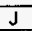 & $\mathrm{F}$ & $M$ & $\mathrm{~A}$ & M. & $j$ & J & A & $\mathrm{s}$ & $\mathrm{O}$ & $\mathbf{N}$ & $\mathrm{D}$ & & & & \\
\hline 1 & Project Definition & & & & & & & & & & & & & & & & \\
\hline 2 & FDH letter & & & & & & & & & & & & & & . & & \\
\hline 3 & Concept definition & & & & & & & & & & & & & & & & \\
\hline 4 & Proj.Basis rev A & & & & & & & & & & . & & & & & & \\
\hline 5 & Sludge Data Base rev A & & & & & & & & & & & & & & & & \\
\hline 6 & Process description rev $\mathrm{A}$ & & & & & & & & & & & & & & & & \\
\hline 7 & Process Flow diagram rev $\mathrm{A}$ & & & & & & & & & & & & & & & & \\
\hline 8 & SGN review & & & & & & & & & & & & & & & & \\
\hline 9 & Process Studies & & & & & & & & & & & & & & & & \\
\hline 10 & Dissolution U/UO2 & & & & & & & & & & & & & & & . & \\
\hline 11 & Solid/Liquid Separation & & & & & & & & & & & & & & & & \\
\hline 12 & Removal PCB HNO3 & & & & & & & & & & & & & & & & \\
\hline 13 & TRU leaching from solids & & & & & & & & & & & & & & & & \\
\hline 14 & Precipitation of U & & & & & & & & & & & & & & & & . \\
\hline 15 & Liquid/solid transfer & & & & & & & & & & & & & & & . & \\
\hline 16 & Organic lon Exchange resins Separ. & & & & & & pr & & & & & & & & & & \\
\hline 17 & Safeguards & & & & & & & $c[0.2]$ & & & & & & & & & \\
\hline 18 & Removal of PCB from solid & & & & & & & & & & & & & & & & \\
\hline 19 & Solids processing & & & & & & & & & & & & & & & & \\
\hline 20 & Dissolver off gas & & & & & & & roc & & & & & & & & & \\
\hline 21 & Safety Studies & & & & & & & & & & & & & & & & \\
\hline 22 & Criticality transport & & & & & & & & & & & & & & & & \\
\hline 23 & chem. react. transp. & & & & & & & & & & & & & & . & & \\
\hline 24 & shielding calc.transp & & & & & & & & & & & & & & & . & \\
\hline
\end{tabular}




\section{SLUDGE TREATMENT SYSTEM}

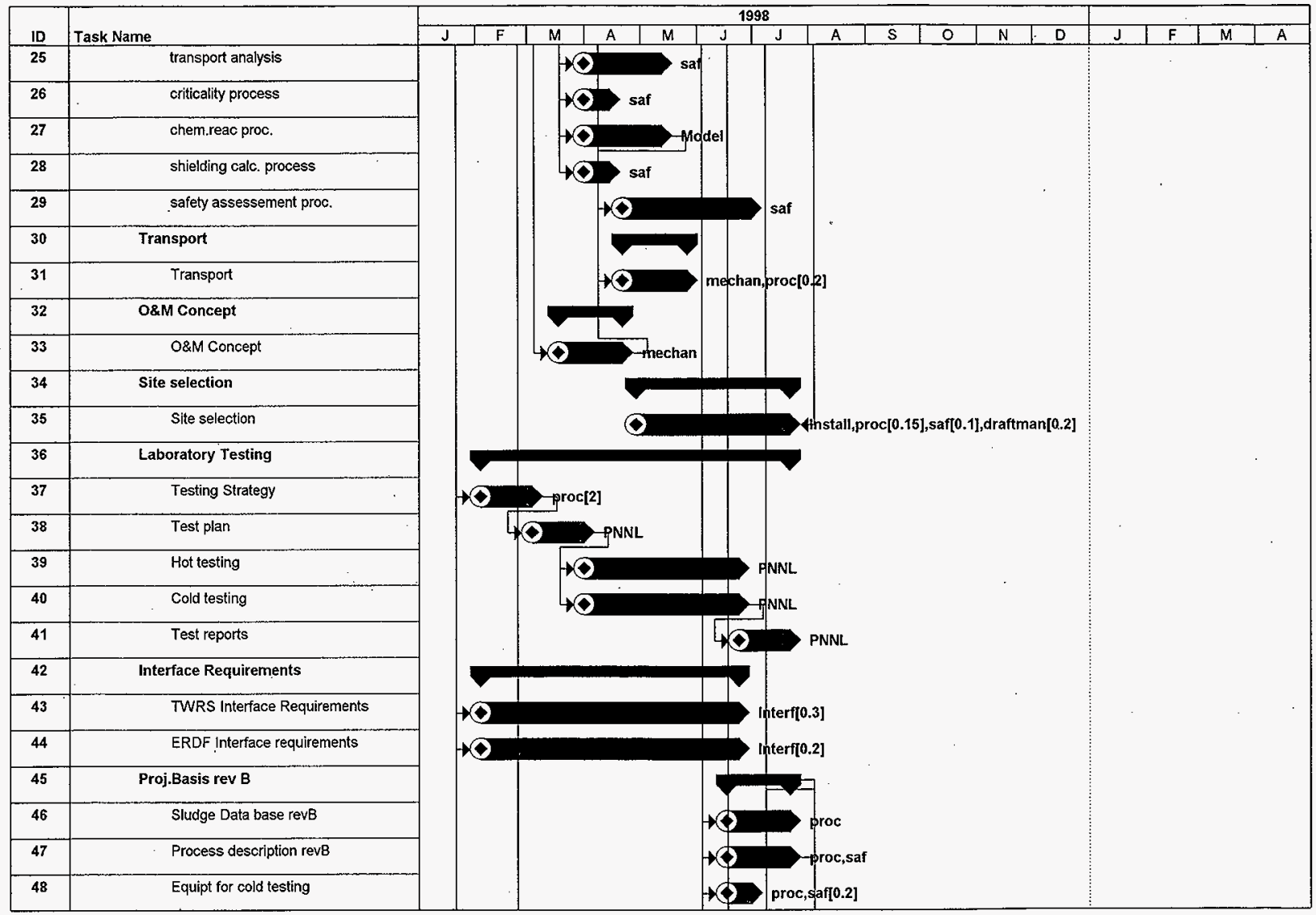




\section{SLUDGE TREATMENT SYSTEM}

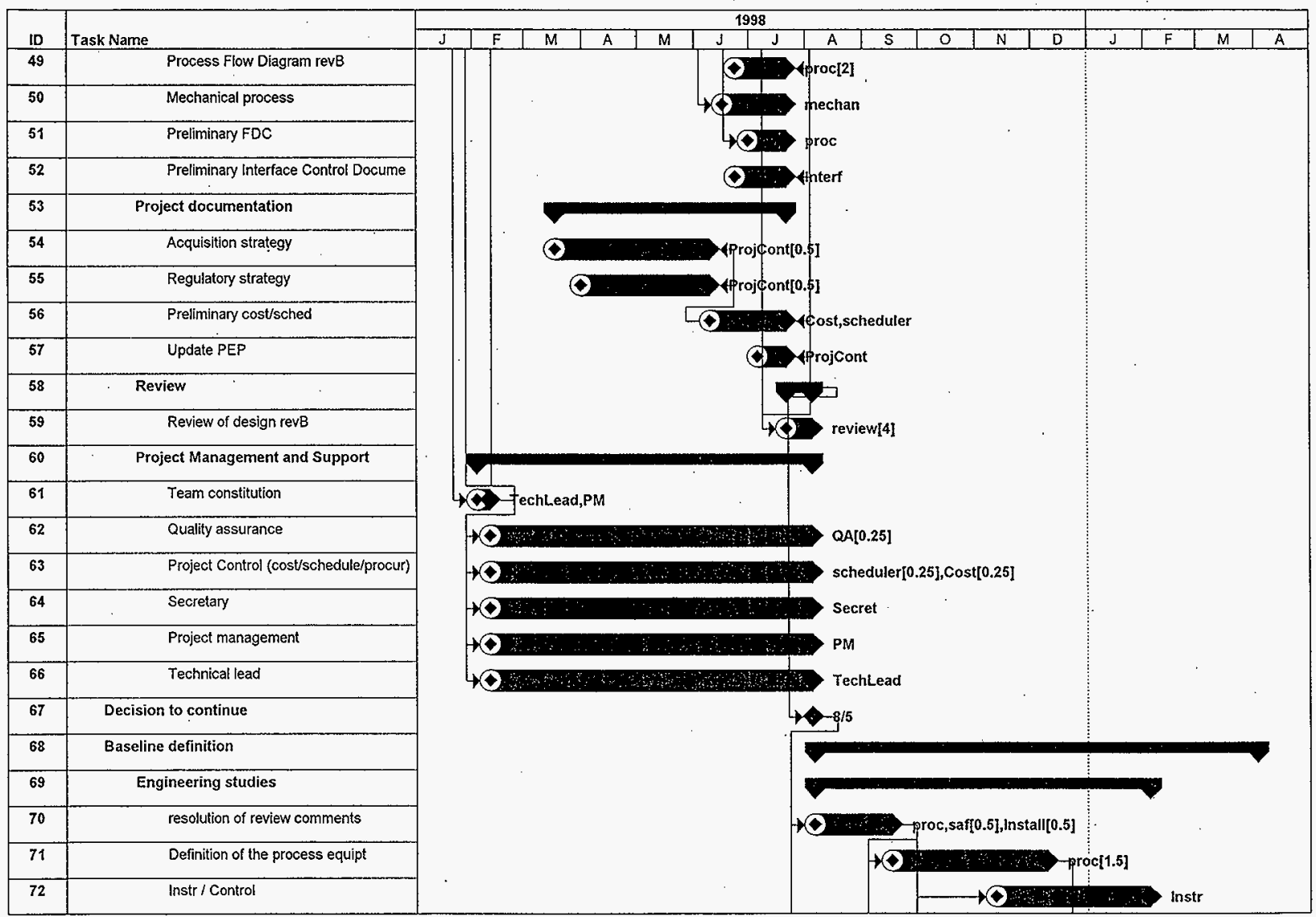




\section{SLUDGE TREATMENT SYSTEM}

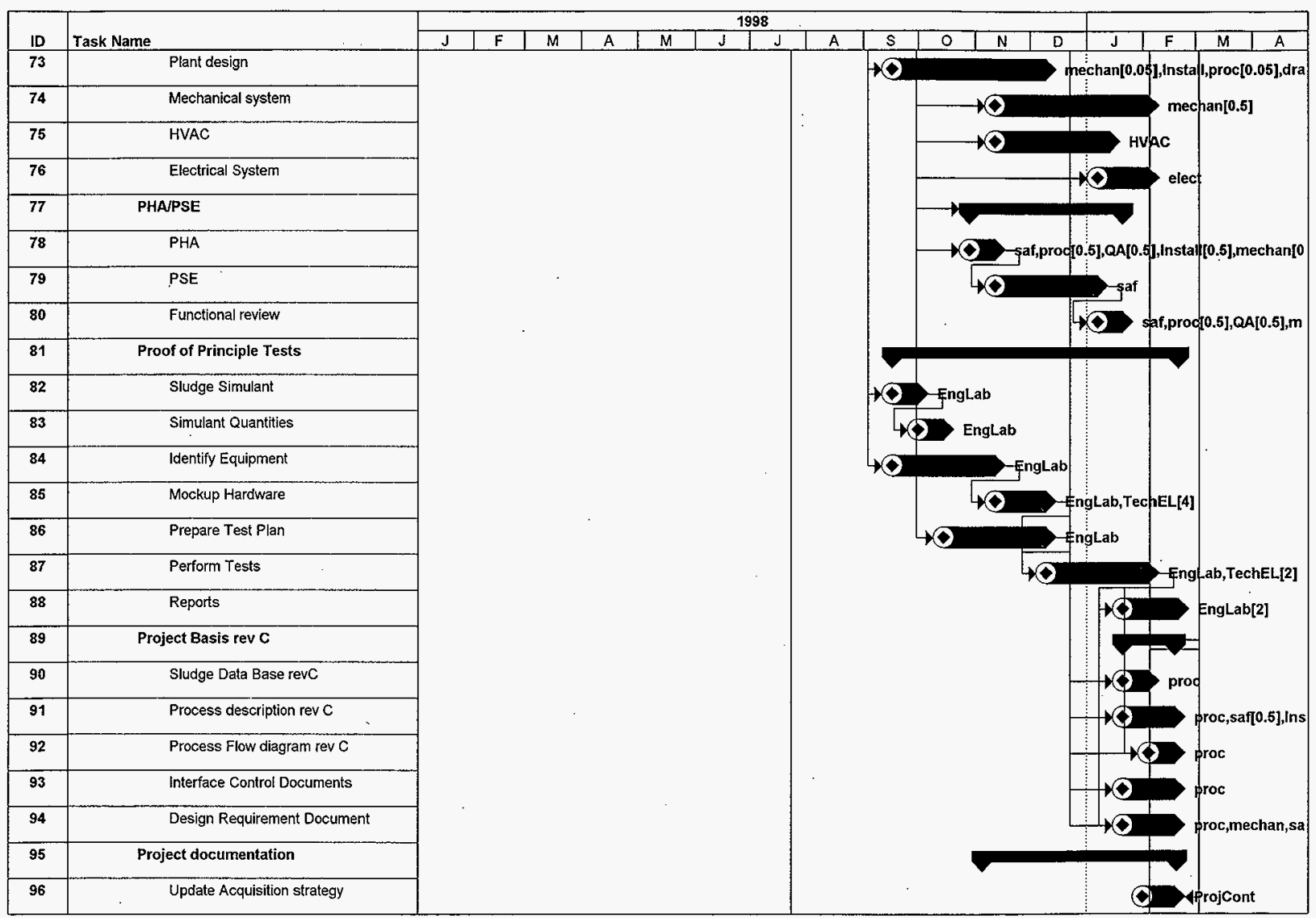


SLUDGE TREATMENT SYSTEM

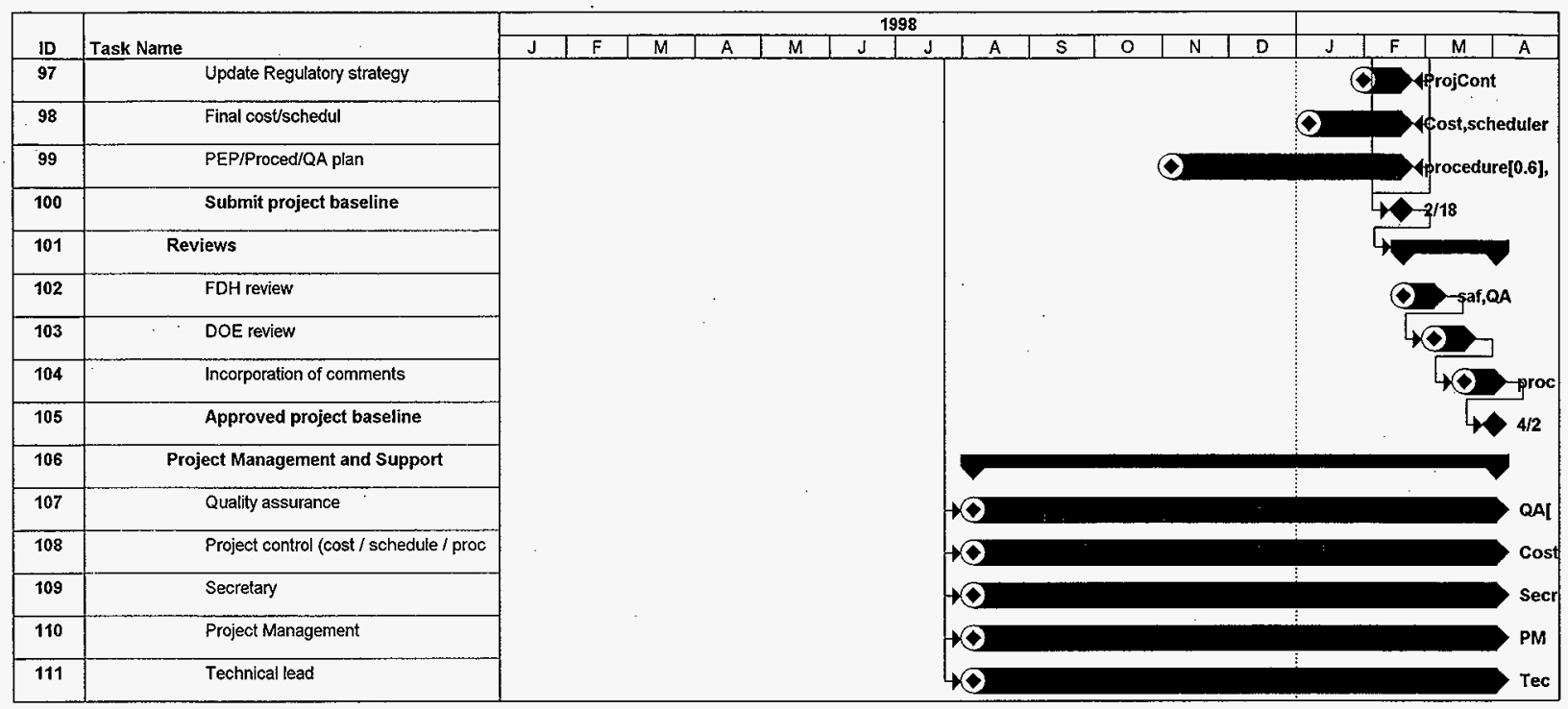




\begin{abstract}
APPENDIX D
SLUDGE TREATMENT PROJECT

PRELIMINARY WORK BREAKDOWN STRUCTURE

DICTIONARY

HNF-2281

Revision 0
\end{abstract}




\section{SLUDGE TREATMENT PROJECT PRELIMINARY WORK BREAKDOWN \\ STRUCTURE DICTIONARY \\ APPENDIX D \\ Rev 0 \\ HNF-2281}

\subsection{PROJECT DEFINITION}

This element encompasses the testing, engineering, and management activities necessary to develop the project concept and establish the project baseline. (See Appendix B for a detailed description for this Work Breakdown Structure (WBS) element.)

\subsection{Concept Definition}

This task will consist of a series of studies and tests to resolve technical and safety uncertainties concurrent with the development of a reference concept to formulate a preliminary basis for the project baseline.

\subsection{Baseline Definition}

This task will build on the concept defined in the earlier phase and will produce a reference design with a corresponding schedule and cost estimate that will become the project baseline. A Project Execution Plan (PEP) will be produced to reflect the baseline and establish the management principles and processes to be used to manage the project execution phase.

\subsection{SYSTEM ACQUISITION}

This WBS element includes all of those activities necessary to design, procure and install a system that will treat the K Basin sludges to meet the Tank Waste Remediation System (TWRS) requirements. The following elements assume a conventional process to design and build the system. Acquisition options will be explored in the Baseline Definition phase which may significantly effect the method of performance which could in turn dictate a change to this WBS structure.

\subsection{Engineering}

This task covers the production of system and discipline drawings, specifications, design basis calculations, test procedures, design reviews, and a final design report. It also includes development of safety and regulatory compliance documents such as the Safety Analysis Report, permits and Standards/Requirements Identification Document (S/RID) revisions. Required spare 


\section{SLUDGE TREATMENT PROJECT Rev 0 PRELIMINARY WORK BREAKDOWN STRUCTURE DICTIONARY APPENDIX D

parts will be identified.

Fabrication/Installation/Construction

This element includes those activities necessary to procure, fabricate, and install the process equipment/treatment system in an appropriate facility in accordance with the design. It includes any facility modifications necessary to accommodate the system.

\subsection{STARTUP/TESTING/TURNOVER}

This element includes the operational testing necessary to confirm that the system meets the project requirements and is ready for operations. It also includes producing or assembling appropriate operating procedures, essential drawings, and operations and maintenance manuals. Spare parts will be procured. The activity will culminate in the turnover of a complete facility and system to the operating contractor.

\subsection{PROJECT MANAGEMENT}

This element includes those tasks during the system acquisition and startup/testing phases to maintain cost, schedule, and technical baseline control and reporting, change control, administrative systems tasks, critical decision processes and quality assurance. 


\section{CORRESPONDENCE DISTRIBUTION COVERSHEET}

Author

W. C. MiTler, 372-0255
Addressee

L. M. Bogart, FDH
Correspondence No.

NHC-9851675

subject: SUBMITTAL OF PROJECT EXECUTION PLAN FOR THE SLUDGE TREATMENT SYSTEM SUBPROJECT

INTERNAL DISTRIBUTION

\begin{tabular}{llll}
\hline Approval & Date & Lame & Location \\
\hline & Correspondence Control & A3-01 & $X$
\end{tabular}

Fluor Daniel Hanford. Inc.

President's office

H5-20

P. S. Blair

R3-11

E. W. Gerber

R3-11

$x$

E. S. McGin]ey

H8-68

R. J. Meyer

G1-57

M. C. Skriba

H8-68

$x$

J. D. Thomson

R3-11

M. J. Wiemers

R3-11

$x$

R. B. Willard

B3-70

N. H. Williams

R3-11

$x$

Numatec Hanford Corp.

J. Bourges

T6-07

$x$

H. D. Chauve

H5-25

A. M. Choho

H6-35

G. P. Chevrier

R3-86

C. Pili-Vincens

R3-86

L. de Lamartinie

H5-61

T. A. Flament

R3-86

W. C. Miller

H5- 25

W. W. Rutherford

R3-25

J. P. Sloughter

H5- 49

$x$

WCM File/LB

H5-25 